\title{
Review
}

\section{Glia: the fulcrum of brain diseases}

\author{
C Giaume $^{1}$, F Kirchhoff ${ }^{2}$, C Matute ${ }^{3}$, A Reichenbach ${ }^{4}$ and A Verkhratsky ${ }^{\star, 5,6}$
}

Neuroglia represented by astrocytes, oligodendrocytes and microglial cells provide for numerous vital functions. Glial cells shape the micro-architecture of the brain matter; they are involved in information transfer by virtue of numerous plasmalemmal receptors and channels; they receive synaptic inputs; they are able to release 'glio'transmitters and produce long-range information exchange; finally they act as pluripotent neural precursors and some of them can even act as stem cells, which provide for adult neurogenesis. Recent advances in gliology emphasised the role of glia in the progression and handling of the insults to the nervous system. The brain pathology, is, to a very great extent, a pathology of glia, which, when falling to function properly, determines the degree of neuronal death, the outcome and the scale of neurological deficit. Glial cells are central in providing for brain homeostasis. As a result glia appears as a brain warden, and as such it is intrinsically endowed with two opposite features: it protects the nervous tissue as long as it can, but it also can rapidly assume the guise of a natural killer, trying to eliminate and seal the damaged area, to save the whole at the expense of the part.

Cell Death and Differentiation (2007) 14, 1324-1335; doi:10.1038/sj.cdd.4402144; published online 13 April 2007

\section{Neuronal Doctrine Challenged: Glial Cells Shape Brain Physiology and Pathology}

'What a piece of work is a man! how noble in reason! how infinite in faculty! in form and moving how express and admirable! in action how like an angel! in apprehension how like a god! the beauty of the world! the paragon of animals! ...'

W. Shakespeare, The tragedy of Hamlet, Prince of Denmark, Act 2, scene 2

The sudden emergence of an intellect, and therefore a human being, which materialised only around a million years ago, remains the main mystery for our self-understanding. Similarly, we still do not know by which steps or transitions the human intellect emerged from the animal kingdom and where the fundamental difference between a man and an animal lies. According to the neuronal doctrine, which governs modern neuroscience since the beginning of the twentieth century, ${ }^{1,2}$ the neurone is regarded as a basic information processing unit consisting of dendrites and axons with a unidirectional flow of information from the receiving dendrites via the integrating cell body to the terminal branches of the axon. Neuronal networks, connected through synaptic contacts, are generally considered as the substrate of our intellect.
The number and size of neural cells increase with the size of the body and of the brain of mammals. This increasing quantity eventually has caused the generation of a new quality, the intellect. Rather amazingly, however, there is a relatively little difference in the morphology and physiology of neurones between humans and beasts; similarly the density of synaptic contacts in the brains of rodents and humans is more or less constant at around $1100-1300$ millions $/ \mathrm{mm}^{3}$. ${ }^{3}$

On the contrary, evolution of the nervous system resulted in great changes in the second type of neural cells, the neuroglia. ${ }^{4}$ Indeed, phylogenetic advance in brain complexity and capabilities coincided with a remarkable increase in the number of glial cells: in the rodent cortex the glial to neurone ratio is about $0.3: 1$, whereas in humans the same ratio is several times higher being B1.65:1, ${ }^{5}$ while the total number of glial cells in the human brain is $\sim 10$ (or even more) times larger than in lesser mammals. Astrocytes in higher primates display a much larger complexity as compared, for example with rodents. ${ }^{4}$ The linear dimensions of human protoplasmic astroglial cells (which are the main type of glia in grey matter) are about 2.75 times larger and their volume is about 27 times greater than for the same cells in a mouse brain. Furthermore, human protoplasmic astrocytes have about 40 main processes and these processes have immensely more complex

${ }^{1}$ INSERM, U840 and Collège de France, Paris, France; ${ }^{2}$ Neurogenetics Max Planck Institute of Experimental Medicine, Hermann Rein Str. 3, 37075, Göttingen, Germany; ${ }^{3}$ Departamento de Neurociencias, Universidad del Pais Vasco, Spain; ${ }^{4}$ Paul Flechsig Institute of Brain Research, Faculty of Medicine, University of Leipzig, Jahnallee 59, 04109, Leipzig, Germany; ${ }^{5}$ Faculty of Life Sciences, The University of Manchester, Oxford Road, Manchester, M13 9PT, UK; ${ }^{6}$ Institute of Experimental Medicine, ASCR, Videnska 1083, 14220 Prague 4, Czech Republic

${ }^{*}$ Corresponding author: A Verkhratsky, Faculty of Life Sciences, The University of Manchester, 1.124 Stopford Building, Oxford Road, Manchester M13 9PT, UK. Tel: + 44161 2755414; Fax: + 44161 2755463; E-mail: alex.verkhratsky@manchester.ac.uk

Keywords: glia; astrocyte; oligodendrocyte; microglia; reactive gliosis; brain pathology; brain damage and repair

Abbreviations: AMPA, $\alpha$-amino-3-hydroxy-5-methylisoxazole-4-propionic acid; BDNF, brain-derived neurotrophic factor; bFGF, basic fibroblast growth factor; CNS, central nervous system; CNTF, ciliary neurotrophic factor; Cx, connexin; EAAT-1 and EAAT-2, excitatory amino-acid transporters type 1 and 2; EAE, experimental autoimmune encephalomyelitis; GABA, $\gamma$-aminobutyric acid; GFAP, glial fibrillary acidic protein; IL-1 $\beta$, interleukin $1 \beta$; iNOS, inducible form of nitric oxide synthase; MCP-1, monocyte chemotactic protein-1; MS, multiple sclerosis; NMDA, $N$-methyl-D-aspartate; PVL, periventricular leukomalacia; PVR, proliferative vitreoretinopathy; ROS, reactive oxygen species; RPE, retinal pigment epithelial; TNF- $\alpha$, tumour necrosis factor- $\alpha$; TrkB, tyrosine kinase B receptor; VEGF, vascular endothelial growth factor.

Received 31.1.07; revised 08.3.07; accepted 09.3.07; Edited by P Nicotera; published online 13.4.07 
branching than mouse astrocytes (which bear only 3-4 main processes). As a result, every human protoplasmic astrocyte contacts and enwraps $\sim 2$ million of synapses compared to only $\sim 100000$ synapses covered by the processes of a mouse astrocyte. ${ }^{4}$

In addition to these quantitative changes, central nervous system (CNS) of Homo sapiens and other primates developed specific types of astroglia, the interlaminar astrocytes and polarised astrocytes, ${ }^{4,6,7}$ which are absent from the brain of other species. The occurrence of interlaminar astrocytes is a very recent achievement of primate evolution. They first appear in the old world monkeys and are absent from new world monkeys. Interlaminar astrocytes are thought to provide for information transfer between different cortical layers. Their somata lie mainly within layer 1 among the axonal fibres that connect different regions of the brain. It is tempting to speculate that the interlaminar processes receive signals that are integrated at the soma level and afterwards transferred to axonal fibre tracts. The glial cells, hence, may be much more important in contributing to higher brain function, not to speak of intellect, as was previously thought.

Past two decades brought upon us an incredible increase in knowledge about appearance, physiological properties and functions of glia (see for review for example ${ }^{8-10}$ to name but a few). We learned that these cells (and especially astroglial cells - Figure 1) are as diverse as neurones; they shape the micro-architecture of the brain matter; they are capable of expressing the same receptors and channels as neurones do; they receive synaptic inputs; they are organised as communicating networks; they are able to release 'glio'transmitters and produce long-range information exchange; finally they act as pluripotent neural precursors and some of them are, most likely, neural stem cells, which provide for adult neurogenesis. These advances in gliology constitute a tremendous

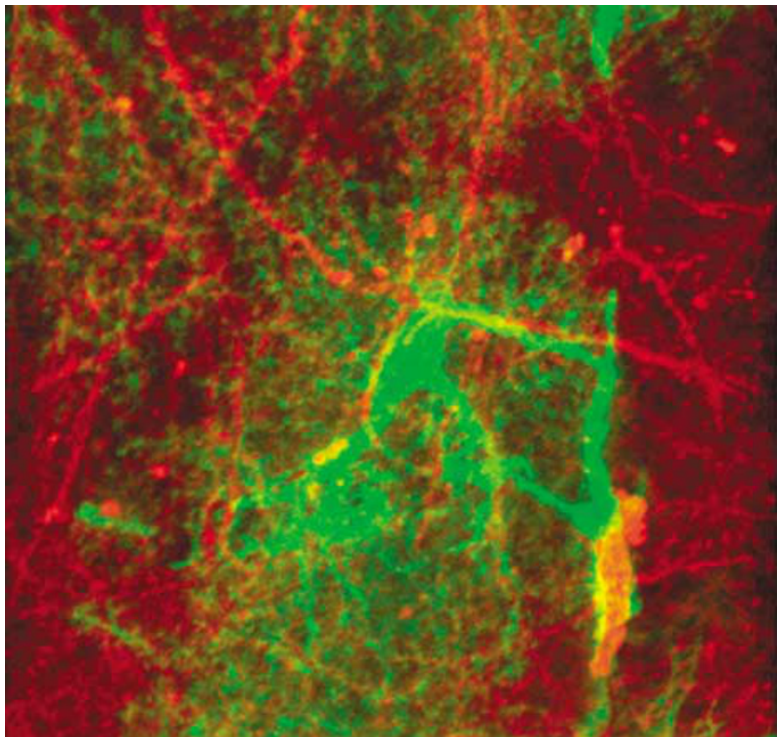

Figure 1 Confocal laser-scanning micrograph of a cortical astrocyte recorded from a double-transgenic mouse in which astrocytes express EGFP and neurones the red fluorescent protein HcRed1. Note the polarised shape of the astrocyte: one endfoot is contacting a brain capillary, whereas thousands of distal processes are in close contact to synapses challenge to the neuronal doctrine, calling for a fundamental reshaping of our perception of the brain organisation, which undeniably will lead to an appearance of a more inclusive theory of brain function.

Similarly, our perception of brain pathology, which, for a long time was revolving around neuronal reactions, their survival or death, has now turned into investigations which very much emphasised the role of glia in the progression and handling of the insults to the nervous system. The brain pathology, is, to a very great extent, a pathology of glia, which, when falling to function properly, determines the degree of neuronal death, the outcome and the scale of neurological deficit.

Indeed, glial cells are fundamental in determining neuronal well-being and in providing all lines of defences to CNS. The astroglia are forming neuronal-glial-vascular units in which astrocytes forge the functional link between synaptic activity and functional hyperaemia; simultaneously astrocytes feed active neurones through the glucose-lactate shuttle. ${ }^{11,12}$ Astroglia rules over extracellular homeostasis in the brain through controlling interstitial concentration of neurotransmitters (and most importantly the naturally toxic, yet the most abundant neurotransmitter glutamate $\left.{ }^{13}\right)$, ions $\left(\mathrm{K}^{+}\right.$buffering, ${ }^{14}$ ) and regulating movements of water. ${ }^{15}$ In addition, brain insults invariably trigger reactive astrogliosis, which reflects the ancient and conserved astroglial defence reaction. ${ }^{16}$ The astrogliosis is fundamental for both limiting the areas of damage (by scar formation through anisomorphic astrogliosis) and for the postinsult remodelling and recovery of neural function (by isomorphic astrogliosis).

Similarly, the second macroglial cell type, the oligodendrocytes ensure the proper function of axons, by myelinating the latter. Damage to oligodendrocytes triggers Wallerian degeneration and invariably results in axonal demise. ${ }^{17}$ Finally, the microglia, which populates the whole of the brain parenchyma and dwells in relatively independent territorial domains, is the only system of specific immune and cellular defence, residing beyond the blood-brain barrier. ${ }^{18}$ Malfunction of glia therefore is fatal for the nervous system; all in all glial cells can survive and operate in the presence of dead or dying neurones; neurones, however, cannot survive in the absence of glia.

In this paper, we shall overview only some of many aspects of glial control over damage and repair in the nervous tissue, specifically concentrating on the astroglial gap junctions and neuroprotection, on the role of Müller glial cells in retinopathies, on the dynamics of microglia and on the oligodendrocytes and white matter damage.

\section{Glia and Neuropathology: General Perspectives}

The brain, the most complex organ in our body, has to function over a long time at the same time adapting to permanently changing environmental challenges. As a result, the brain circuitry has to be exceptionally plastic, and indeed many brain areas (for example hippocampus or the visual cortex) are prone to a constant remodelling. Other brain regions, responsible for vital functions such as breathing, should rigidly adhere to a conserved structure. This implies the necessity of autoregulatory systems, which control all aspects of brain development and function. To achieve this, the 
brain is isolated from the rest of the organism so that it can control itself efficiently. This border is formed by the bloodbrain barrier. Astroglial endfeet plaster the blood vessels and induce tight junctions among neighbouring endothelial cells of the brain capillaries. Selective uptake and transport mechanisms in endothelial and astroglial membranes are essential for most components of the blood stream to enter the brain. Further, control over homeostasis in the brain parenchyma is of a paramount importance and these are the glial cells that act as creators and defenders of this homeostasis. As a result glia appears as a brain warden, and as such it is intrinsically endowed with two opposite features: it protects the nervous tissue as long as it can, but it also can act as a natural killer, trying to eliminate and seal the damaged area, to save the whole at the expense of the part.

This two-sided role of glia is particularly exemplified upon ischaemic brain insults. ${ }^{19}$ Disruption of the blood flow in the brain causes considerable damage and death of neural cells. Reduced oxygen supply (either hypoxia or anoxia) triggers rapid depolarisation of neurones, and greatly compromises their ability to maintain transmembrane ion gradients. This is manifested in $\mathrm{Na}^{+}$and $\mathrm{Ca}^{2+}$ influx into the cells together with a substantial $\mathrm{K}^{+}$efflux; massive $\mathrm{Ca}^{2+}$ influx initiates glutamate release from neuronal terminals, thus further amplifying the vicious circle by inducing 'glutamate excitotoxicity'. ${ }^{20}$

Neurones and oligodendrocytes are the most vulnerable and sensitive to ischaemic shock and glutamate excitotoxicity; astrocytes are generally (but not always) more resilient. The predominant mechanism of cell death, which follows the stroke, is associated with excessive activation of ionotropic glutamate receptors; particularly important is the long-lasting opening of highly $\mathrm{Ca}^{2+}$ permeable $\mathrm{N}$-methyl-D-aspartate (NMDA) receptors. The latter are expressed in majority of neurones, in several types of astrocytes and in many oligodendrocytes $^{21}$; in all these cells overactivation of NMDA receptors is pathologically relevant. The final result of exocytotic signalling cascades is the cell overload with $\mathrm{Ca}^{2+}$, which strains metabolic processes, impairs upon mitochondrial function and activates numerous death-related enzymes thus driving cells to fatal end through apoptotic or necrotic route. 22

The main brain defence against glutamate excitotoxicity is formed by astrocytes. Astroglial cells, by virtue of numerous transporters residing in their membrane, act as the main sink for the glutamate in the CNS (see for example ${ }^{13}$ for review). Astroglial protection against glutamate excitotoxicity became very obvious from in vitro experiments: withdrawal of astrocytes from neuronal cultures invariably produced a very significant increase in the neuronal death triggered by glutamate administration. ${ }^{13}$ On a more general level, pharmacological or genetic downregulation of glial glutamate transporters exacerbates brain damage. In addition, astrocytes, which contain high concentrations of main antioxidants glutathione and ascorbate, protect the brain against reactive oxygen species, which are invariably produced upon ischaemia. Finally, being the main site for potassium buffering, astroglia removes the excess of $\mathrm{K}^{+}$ from extracellular space, which may restrain neuronal depolarisation.
The same mechanisms, however, underlie the darker side of astroglial responses to ischaemic insults; when injury is too severe astroglial cells may exacerbate damage of neural tissue. First, astrocytes may act not only as a sink, but also as a source of glutamate. Indeed, concentration of the latter in astroglial cytoplasm may reach the level of several (up to 10) $\mathrm{mM}$. Depolarisation of astrocyte membrane together with an increased extracellular $\mathrm{Na}^{+}$concentration can reverse glutamate transporter, ${ }^{23}$ thus producing glutamate efflux. Further, glutamate may leave the astrocytes through hemichannels, which can be opened by lowering of extracellular $\mathrm{Ca}^{2+}$ and acidosis or even through $\mathrm{P} 2 \mathrm{X}_{7}$ receptors, activated by excessively high extracellular ATP; all these do happen during ischaemia. ${ }^{24}$ Second, astrocytes may spread the death signals through the brain parenchyma via gap junctions ${ }^{25}$ and/ or participate in developing spreading depression, which determine the infarction progress through the penumbra.

\section{Intercellular Communication in Glia and Neuroprotection}

Connexins in glia. In the brain, a typical, but not exclusive, property of glial cells is prominent expression of connexins (Cxs), the molecular constituents of gap junction channels that allow direct intercellular communication between adjacent cells. ${ }^{26}$ When expressed at the membrane, Cxs are organised as hexamers, which, when associated headto-head between two neighboring cells, form a full gap junction channel. Recent works have also demonstrated that Cxs can operate as hemi-channels allowing transplasmalemmal matters exchange. ${ }^{27}$ The central pore defined by hemi- or full- Cx channels accounts for passage of ions and small molecules with a cutoff selectivity of about $1-1.2 \mathrm{kDa}$. Cxs constitute a multigenic family of 20 or 21 members in rodents and humans, respectively, and so far at least 11 different Cxs (Cx26, Cx29, Cx30, Cx32, Cx36, Cx37, $\mathrm{Cx} 40, \mathrm{C} \times 43, \mathrm{C} \times 45, \mathrm{C} \times 46$ and $\mathrm{Cx} 47$ ) have been detected in the brain. Numerous studies have shown that biophysical properties, compatibility of assembly between defined Cxs, permeability and regulation of $\mathrm{Cx}$ channels depend on the nature of their molecular constituents leading to the concept of a 'language' of $\mathrm{Cx} .{ }^{28}$ This concept, initially proposed for gap junction channels, may now be extended to hemichannels as several 'gliotransmitters' can be released through the latter and activate neighbouring glial cells and neurones. In situ pattern of Cxs expression is distinct for each brain cell type and all of them contain more than one $\mathrm{Cx}$ suggesting that the properties and role of full- and hemichannels are cell specific.

Although the first evidence of gap junction-mediated communication was demonstrated by electrophysiological recordings of electrical coupling between excitable cells, the permeability of $\mathrm{Cx}$ channels for small molecules is probably more important for signalling between nonexcitable cells, such as glia. Thus, addressing the question of the role of glial Cxs requires the identification of signalling molecules exchanged through this intercellular pathway. There is now converging evidence indicating that intercellular exchange of signalling molecules occurs in cultured astrocytes and in 
glioma cell lines transfected with Cxs. ${ }^{29}$ The permeability of astrocyte gap junctions for glucose and its metabolites, including lactate, has been initially characterised by using radiolabelled compounds. More recently, this has been confirmed by using a fluorescent glucose molecule 2-( $\mathrm{N}-(7-$ nitrobenz-2-oxa-1,3-diazol-4-Y1)amino)-2-deoxyglucose. ${ }^{30}$ Furthermore, Cx full- and hemi-channels are also instrumental to the propagation of intercellular $\mathrm{Ca}^{2+}$ waves thanks to their permeability for $\operatorname{InsP}_{3}$ (intercellular route) and ATP (extracellular route). ${ }^{28}$

The level of $\mathrm{Cx}$ expression in most glial cells is high compared to neurones, and this high expression persists throughout adulthood. Morphological, biochemical and functional studies carried out in vitro as well as in situ indicate that each glial cell type expresses a set of distinct Cxs, none of them being specific for glia and that the strength of coupling and the level of $\mathrm{Cx}$ expression depends on the glial subtype, the developmental stage and the brain region.

Astrocytes. Cx43 is the main Cx detected in cultured astrocytes. $^{26}$ When astrocytes are isolated from Cx43 knockout mice, coupling is reduced to $\sim 5 \%$ of the control. This residual coupling is provided by small amounts of other Cxs, in particular Cx30, Cx40, Cx26, Cx46 and Cx45. Similarly, expression of multiple Cxs mRNAs in astroglia was revealed by single-cell RT-PCR performed on astrocytes from hippocampal brain slices. ${ }^{31}$ Nevertheless, Cx30 and $\mathrm{Cx} 43$ are considered the main Cxs expressed in situ in astrocytes. Interestingly, Cx43 expression and coupling efficiency vary in cultured astrocytes derived from different brain regions. Similar heterogeneity was also found between and within brain regions studied in acute slices. ${ }^{32}$ Moreover, Cx30 is only expressed in astrocytes of mature grey matter, and the relative levels of Cx43 and Cx30 vary according to the developmental stage and region studied. ${ }^{33}$ Although still debated, ${ }^{34}$ the presence of Cx26 was also reported in sub-population of astrocytes. ${ }^{35}$

Oligodendrocytes are endowed with gap junctions found in almost all areas of their plasma membranes, however, they were not detected between successive layers of myelin. ${ }^{36}$ As shown in culture and in brain slices, the coupling efficiency between oligodendrocytes is low compared to astrocytes. Expression of $\mathrm{C} \times 32$ and $\mathrm{C} \times 47$ has been shown in oligodendrocytes studied in vitro and in vivo. ${ }^{37}$ Distribution of $\mathrm{Cx}$ sybtypes in adult brain sections suggests differences in their subcellular localisation with $\mathrm{C} \times 32$ expression appearing first coincidentally with the start of myelination. ${ }^{38}$ Expression of a gene reporter indicates that $\mathrm{Cx} 29$ is also present in oligodendrocytes in the white and grey matters. ${ }^{39}$

Microglial cells. Although nonactivated microglia lack Cx43 expression in culture it has been detected in adult rat cerebral cortex. The expression of $\mathrm{Cx} 43$ is increased after activation of microglial cells in vivo after a stab wound. In this case, Cx43 is observed at the interfaces between activated cells, which become dye-coupled through gap junctions. ${ }^{40}$

The expression of glial connexins is affected in brain inflammation. Brain inflammation is a hallmark of many brain diseases and it is characterised by a reactive gliosis associated with phenotypic changes and proliferation of glial cells (mainly astrocytes and microglia). These changes are accompanied by modifications of $\mathrm{Cx}$ expression in astrocytes, as complex changes in Cx43 expression and gap junctional communication have been observed after brain injuries and pathologies known to be associated with reactive gliosis. ${ }^{41}$ During brain inflammation, microglial cells and astrocytes synthesise a variety of inflammatory mediators that regulate $\mathrm{C} \times 43$ expression and gap junctional communication in astroglia. For instance, exposure of cultured astrocytes to interleukin $1 \beta(\mathrm{IL}-1 \beta)$ downregulates their content of $\mathrm{Cx} 43$ at both mRNA and protein levels. ${ }^{42}$ This effect is potentiated by another proinflammatory cytokine tumour necrosis factor- $\alpha$ (TNF- $\alpha)$ as well as by $\beta$-amyloid. These inhibitory effects are reproduced by co-culturing astrocytes with activated microglia known to release proinflammatory cytokines, indicating that tight interaction occur between glial partners involved in reactive gliosis. ${ }^{43}$ The functional consequences of this inflammation-induced Cx inhibition in astrocytes are not fully understood, however, one possibility is that the decrease in Cx-mediated communication may restrict the passage of active molecules to neighbouring cells thus isolating the primary lesion site. Therefore, reactive astrocytes with modified intercellular communication should be considered as key elements in a dynamically changing environment that is likely to modify neuronal functions and survival.

\section{Intercellular communication in astrocytes is either neuro-} protective or deleterious. Given the high expression of Cxs, the extent of gap junctional communication among astrocytes and their role in spatial buffering of ions (potassium, $\mathrm{Ca}^{2+}$ ), long-range signalling and exchange of small permeating molecules (glutamate, ATP, glucose) within astroglial syncytium, a neuroprotective role for astrocyte gap junctions has been hypothesised. Alternatively, Cx-mediated intercellular communications have been implicated in the propagation of cellular injury between astrocytes. These contrasting opinions are based, in part, on experimental brain ischaemia models and on the clinical impact of such injuries. ${ }^{44}$ Several observations support a neuroprotective role of astrocyte Cxs: (i) the pharmacological inhibition of astrocyte gap junctions enhances neuronal vulnerability either to glutamate cytotoxicity or metabolic stress in neurone/glial co-cultures as well as under experimental ischaemia using oxygen and glucose depletion in hippocampal slice cultures; (ii) in vivo, following middle cerebral artery occlusion, heterozygote $\mathrm{C} \times 43^{+/-}$mice show a significantly increased stroke volume compared to wild-type mice; and (iii) the use of targeted deletion of $\mathrm{Cx} 43$, specifically in astrocytes, provides further evidence that these proteins play a neuroprotective role in ischaemic insults. On the other hand, evidence that gap junctions enhance neuronal injury is also supported by several observations. That is, (i) neuronal death caused by oxygen and glucose depletion is decreased when Cx43 expression is blocked by specific antisense oligodeoxynucleotides in hippocampal slice cultures; (ii) the stroke volume following occlusion of the medial cerebral artery is reduced by gap junction inhibitors, and (iii) the spreading depression caused by ischaemic insult propagates via astrocyte gap junctions remaining open, a process that 
results in the expansion of the stroke volume. The role of astroglial Cxs could also be mediated by hemi-channel opening. Indeed, it has been recently reported that $\mathrm{Cx}$ hemichannels, which are normally closed became open under experimental ischaemia induced by glucose and oxygen deprivation. $^{24}$

Up-to-now, a number of factors may account for the above apparent contradictions. ${ }^{44}$ For instance, experimental studies vary considerably with regard to the systems employed and the way used to block hemi- or full- $\mathrm{Cx}$ channel-mediated communication. In particular, chronology is likely an important parameter to be considered. All in all, gap junctions as well as hemi-channels may be beneficial at a defined step in the injury cascade but deleterious when considered at another time. Also, for a defined brain damage, the change in the level of $\mathrm{Cx}$ expression is different in the core and at the periphery of the damaged site, a process that likely depends on the nature of the $\mathrm{Cx}$ involved ( $\mathrm{Cx} 43$ versus $\mathrm{Cx} 30$ ). Finally, the contribution of Cxs is certainly different when these proteins work as hemi- or full-channels. Indeed, as each of these membrane channels provides a pathway for intercellular communication, it is not yet established that they target the same cellular partner (neurones, astrocytes, oligodendrocytes and microglia) and that they allow the movement of the same signalling molecules. These critical distinctions will become clear when specific pharmacological tools discriminating between different Cxs, or between hemi- and full-channels will be available.

\section{Müller Cells and Retinopathy}

The retina, although being a highly specialised sensory organ, is often used as a 'simple', veritable model of the brain. To study the impact of glia in neurodegeneration, the mammalian retina indeed offers numerous advantages. First, it contains a peculiar type of macroglial cells, the so-called Müller (radial glial) cells, either as the only type (in avascular retinae) or as the dominant type of macroglia (in vascularised retinae, astrocytes are additionally located in the innermost retinal layers). Second, the well-layered structure of the retinal tissue greatly facilitates both the identification and the quantification of the neuronal cell type(s) undergoing degeneration. Third, all neuronal compartments (somata, processes, synapses) and non-neuronal elements of the retina and its environment (blood vessels, vitreous body) form intimate contacts with the branches of the Müller cells, each of which spans the entire retinal thickness. This latter condition, together with their biochemical and physiological properties, enables the Müller cells in the healthy retina to perform a wealth of crucial interactions with the neurones, to guarantee their developmental maturation, nutrition, normal function, and survival (Figure 2a). ${ }^{45}$

However, this symbiosis between the Müller cells and their 'assigned' neurones, ${ }^{45}$ advantageous as it normally is, causes dramatic problems for neuronal survival when the Müller cells stop patronising neurones. Unfortunately, these are not rare events; rather, a de-differentiation of Müller cells ('reactive Müller cell gliosis') occurs in many acute and chronic retinal injuries and diseases. Then, the neurones are endangered not only by the loss of supportive glial functions, but also by additional Müller cell reactions which often are directly detrimental to them (Figure $2 \mathrm{~b}$ ). ${ }^{45}$

This 'Janus-faced' Müller cell impact on retinal neurones can be better understood when one considers the essential physiological features of these glial cells. The plasma membrane of Müller cells is highly permeable to $\mathrm{K}^{+}$as a consequence of the high density of specialised $\mathrm{K}^{+}$channels. The high $\mathrm{K}^{+}$permeability sets a very negative membrane potential of these cells, which is close to the equilibrium potential for $\mathrm{K}^{+}$(about $-80 \mathrm{mV}$ ), which, together with the specific subcellular distribution of distinct $\mathrm{K}^{+}$channel types, is an essential precondition for virtually all neurone-supportive functions of these cells. In particular, inwardly rectifying $\mathrm{K}^{+}$ channels containing the $\mathrm{K}_{\mathrm{ir}} 4.1$ subunit are concentrated in perivascular membrane sheets, and at the inner and outer limiting membranes. ${ }^{46}$ These channels are responsible for the export of excess $\mathrm{K}^{+}$from retina into extraretinal 'sinks' such as the blood vessels, the vitreous body and the subretinal space. $\mathrm{K}^{+}$ions are released into the perisynaptic extracellular clefts by active neurones, from where they enter the Müller cells via the channel complexes containing the $\mathrm{K}_{\mathrm{ir}} 2.1$ subunit ${ }^{46}$; this process of retinal $\mathrm{K}^{+}$clearance has been termed ' $\mathrm{K}^{+}$siphoning'. ${ }^{47}$ The $\mathrm{K}^{+}$ions can leave the retina by this mechanism only together with water molecules, for osmotical reasons. This provides another essential Müller cell function, namely the clearance of excess water which, for instance, is generated by the aerobic metabolism of retinal neurones (reviewed by Bringmann et al. ${ }^{48}$; see Figure $2 \mathrm{a}$, i).

Another Müller cell function is called 'neurotransmitter recycling' (Figure 2a, II). Müller cells possess high-affinity uptake carriers for retinal neurotransmitters, including glutamate and $\gamma$-aminobutyric acid (GABA), which remove excess signalling molecules from the perisynaptic clefts. They also express glutamine synthetase, which converts glutamate into the nonactive molecule, glutamine. The latter is released back for neuronal uptake and reconversion into glutamate or GABA. ${ }^{49}$ It is noteworthy, that this enzymatic reaction is at the same time the only possibility to remove ammonia from the brain (glutamate + ammonia $\rightarrow$ glutamine + water). An important precondition for transmitter recycling is the highly negative membrane potential of the Müller cells; depolarisation (caused for example by an inhibition or downregulation of $\mathrm{K}^{+}$channels) strongly impairs glial neurotransmitter uptake, because the uptake carriers are electrogenic, and use the membrane potential as a driving force..$^{50}$

There are many more neurone-supportive functions of mature Müller cells, including metabolic symbiosis by 'feeding' of neurones with lactate; clearance of $\mathrm{CO}_{2}$ by the glial carbonic anhydrase, delivery of ROS scavengers such as glutathione (Figure2a, III), and release of neurotrophic growth factors such as basic fibroblast growth factor (bFGF) and ciliary neurotrophic factor (CNTF), partially driven by stimulation of the brain-derived neurotrophic factor receptors of tyrosine kinase B receptor type on Müller cells (Figure 2a, IV). ${ }^{45}$ All these functions require an intact energy metabolism of Müller cells, which is directly or indirectly related to maintenance of negative membrane potential of the cells.

All the above-mentioned normal glia-neurone interactions are supposed to be maintained, and probably even stimulated, in cases of mild and transient retinal injury. However, 
a

(I)

(II)

(III)

(IV)

$\mathrm{K}+$ \& water homoeostasis

Transmitter recycling Radical metabolism

Growth factor release

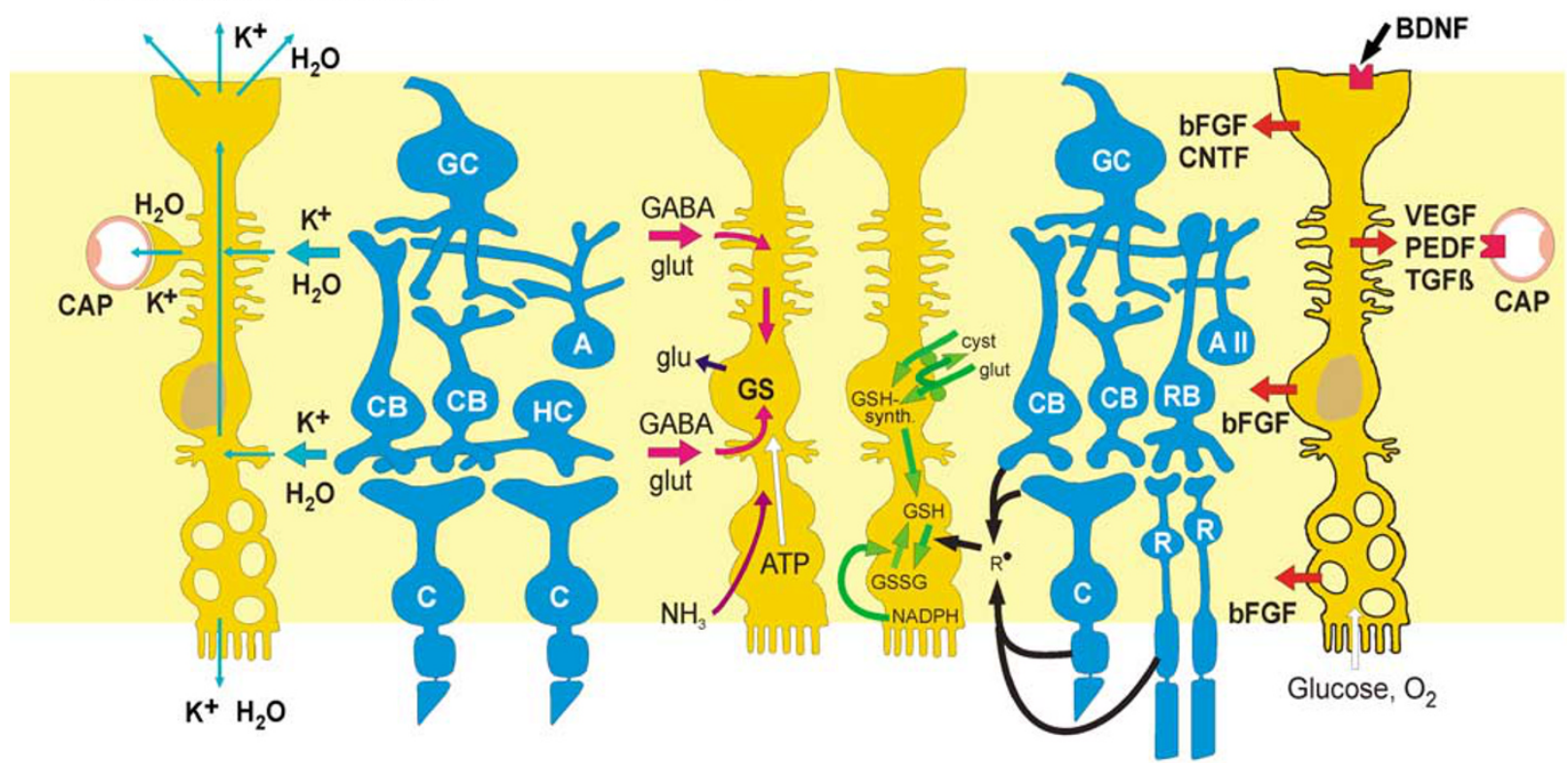

b

(I)

(II)

$\measuredangle \mathrm{K}^{+}$\& water homoeostasis intra- and extracellular edema

4 Transmitter recycling $\rightarrow$ excitotoxicity

(III)

(IV)

altered radical metabolism altered growth factor release

$\rightarrow$ destruction of neurons $\rightarrow$ neuronal cell death,

- Müller cell proliferation
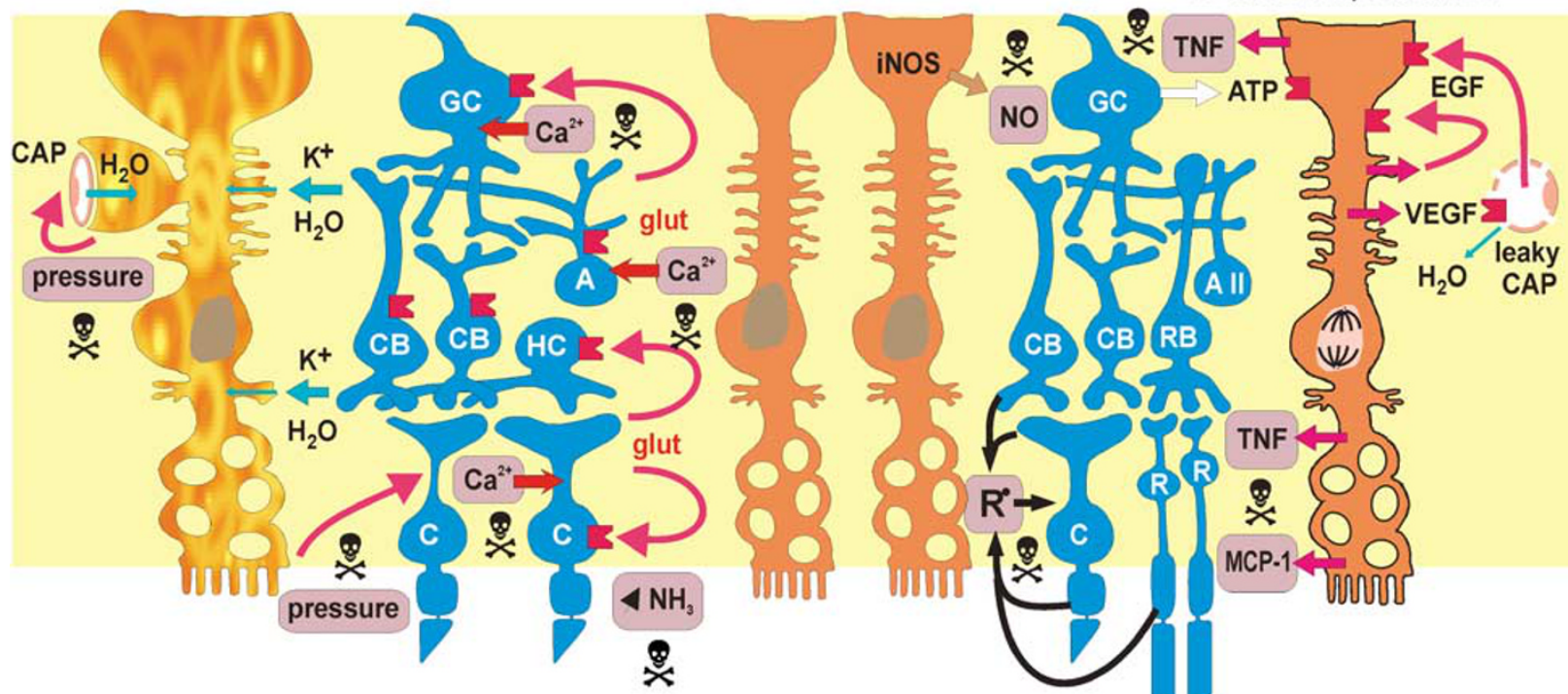

Figure 2 Survey of glia-neurone interactions in the normal and injured retina. (a) Role of Müller (glial) cells in maintaining $\mathrm{K}^{+}$and water homeostasis (I), clearing neurotransmitters (II) and protecting the retina against oxygen free radicals (III). Furthermore, Müller cells release neurotrophic factors (IV). (b) Failure of reactive 'gliotic' Müller (glial) cells to maintain $\mathrm{K}^{+}$homeostasis and to prevent the accumulation of water (I), to clear the retina from excess L-glutamate and ammonia (II), and to neutralise oxygen free radicals is detrimental and may lead to permanent retinal damage (III). Moreover, reactive Müller cells even release nitric oxide (III) and detrimental (amounts of) cytokines such as VEGF (causing leaky blood vessels) and TNF (contributing to neuronal cell death) (IV). Intracellular water accumulation causes glial cell swelling and oedema, which exerts pressure upon retinal blood vessels and neurones (I). Abbreviations: A, amacrine cell; ATP, adenosine triphosphate; bFGF, basic fibroblast growth factor; BDNF, brainderived neurotrophic factor; C, cone photoreceptor; CAP, capillary; CB, cone bipolar cell; CNTF, ciliary neurotrophic factor; cyst, cysteine; EGF, epithelial growth factor; GABA, $\gamma$-aminobutyric acid; GC, ganglion cell; glut, glutamate; glu, glutamine; GS, glutamine synthetase; GSH, glutathione (reduced); GSH-synth, glutathione synthetase; GSSG, glutathione (oxidised); HC, horizontal cell; iNOS, inducible form of nitric oxide synthase; MCP-1, monocyte chemotactic protein-1; NADPH, nicotinamide adenine dinucleotide phosphate, reduced form; PEDF, pigment epithelium-derived factor; $\mathrm{R}$, rod photoreceptor; $\mathbf{R}^{\bullet}$, free radical molecule; RB, rod bipolar cell; TGF $\beta$, tumour growth factor- $\beta ;$ TNF, tumour necrosis factor; VEGF, vascular endothelial growth factor 
more severe retinal damage inevitably triggers 'unwelcome' responses of Müller cells, manifested in reactive gliosis. This process involves an early upregulation of the expression of the intermediate filament protein, glial fibrillary acidic protein, which can be visualised by immunohistochemistry. Further progression of reactive gliosis is accompanied by a dedifferentiation of the cells; a key step consists in a downregulation and redistribution of $\mathrm{K}^{+}$channels in the glial cell plasma membrane. ${ }^{45}$ Particularly, the $\mathrm{K}_{\mathrm{ir}} 4.1$ are no longer enriched in the perivascular and vitreal endfoot membranes of Müller cells, ${ }^{51}$ and the $\mathrm{K}^{+}$conductance of the cell membrane at potentials negative to $-40 \mathrm{mV}$ is strongly reduced or even completely missing. ${ }^{51}$ This is accompanied by a loss of the negative resting membrane potential of the cells; such reactive Müller cells display stochastically scattered membrane potentials up to levels as low as $-20 \mathrm{mV} .^{45,51}$

Thus, the reactive downregulation of $\mathrm{K}^{+}$channels constitutes a switch from neuroprotective functioning of mature glia to a 'private live' of dedifferentiated glial cells which now abandon neurones to an increasing chaos of their waste products. The neurones continue to release $\mathrm{K}^{+}$and glutamate neither of which can be buffered by the Müller cells any longer (Figure $2 \mathrm{~b}, \mathrm{I}$ and $\mathrm{II}$ ), owing to insufficient $\mathrm{K}^{+}$ conductance and altered membrane potential (i.e., missing driving force for glutamate uptake). This causes strong, longlasting depolarisations of the neurones, accompanied by excessive $\mathrm{Ca}^{2+}$ influx and, finally, excitotoxic neuronal death. As a further complication, the insufficient $\mathrm{K}^{+}$siphoning into the blood vessels and other sinks coincides with an impaired water export from the retina, resulting in glial cell swelling. ${ }^{45}$ This glial swelling and the subsequent cellular retinal oedema, is further aggravated by a vascular endothelial growth factor (VEGF)-induced leakiness of the retinal blood vessels (see below) which cause a further drag of water into the retinal tissue (and finally, into the glial cells). There are two conditions which exacerbate the problem; first, $\mathrm{K}^{+}$may still enter the Müller cells because the inwardly rectifying $\mathrm{K}_{\mathrm{ir}} 2.1$ channels remain available in membrane areas facing neuronal $\mathrm{K}^{+}$ release and second, the aquaporin- 4 water channels are still present in the endfoot membranes of Müller cells. Together this may even cause a reversal of the water fluxes at the endfoot membranes, such that now water enters the Müller cell cytoplasm from the blood vessels, rather than vice versa. $^{45}$ In any case, glial swelling and retinal oedema constitute another danger for the survival of the neurones: the swollen glial cells apply pressure on the blood vessels, which decreases retinal supply of oxygen and nutrients, and cause a further accumulation of neuronal waste products, and deliver a pressure on the neurones themselves, thus causing direct mechanical injury (Figure $2 \mathrm{~b}, \mathrm{I}$ ). It should also be kept in mind that the breakdown of neurotransmitter recycling is accompanied by a failure of ammonia clearance, because the glial glutamate uptake is no longer sufficient for a balanced feeding of the glutamine synthetase reaction; increased levels of ammonia contribute to neurotoxicity and neurodegeneration.

Moreover in the course of reactive gliosis, the Müller cells become depleted of glutathione, resulting in impaired defence against free radicals (Figure $2 \mathrm{~b}, \mathrm{III}$ ). Rather, the inducible form of nitric oxide synthase (iNOS) is now expressed by glial cells, which causes an increased exposure of the neurones to ROS. ${ }^{52}$ Finally, the pathological scenario involves a dramatic change in the cytokine release pattern of the Müller cells (Figure 2b, IV). Oedema/pressure-mediated reduction of retinal blood flow and excitotoxic overstimulation of neuronal metabolism contribute to retinal hypoxia which stimulates the release of VEGF from Müller cells ${ }^{53}$ and retinal pigment epithelial (RPE) cells. ${ }^{54}$ Increased VEGF levels make the retinal vasculature leaky, which, in turn, leads to increased efflux of water (i.e., to aggravated oedema) and to the release of a variety of cytokines from vessels into the retinal tissue. Some of these cytokines, such as epithelial growth factor (EGF), are known to stimulate the release of TNF from Müller cells. Finally, Müller cells stop releasing neuroprotective factors such as bFGF and CNTF, but rather flood the neurones with cell death-inducing factors such as TNF and monocyte chemotactic protein-1. ${ }^{55}$

These pathological signalling pathways, further stimulated by the release of ATP from injured neurones and activation of ATP receptors on Müller cells (as well as by their depolarised membrane potential, see above), eventually trigger the entry of Müller cells into the cell cycle (Figure $2 \mathrm{~b}$, IV). ${ }^{45}$ Massive Müller cell proliferation then causes the formation of glial scars, the migration of dedifferentiated Müller cells out of the retina, and the generation of cellular plates or 'membranes' on both surfaces of the retina (Figure 3a). These cellular membranes are constituted by several different cell types, which all are capable of migration and proliferation, such as RPE cells, fibroblasts and retinal glial cells. As they use to grow into the vitreous body (and induce alterations there), this phenomenon is called proliferative vitreoretinopathy (PVR). ${ }^{56}$ Proceeding PVR then leads to folding and detachment of the retina (Figure $3 b$ ), excessive neurodegeneration and blindness.

In summary, normal mature Müller cells display a set of specific features that enable them to perform a wealth of interactions with the retinal neurones. These interactions support the survival and the proper functioning of nerve cells in the healthy retina, and are stimulated in the early stages of mild retinal injury, thus providing neuroprotective action. Upon severe and/or rapidly progressing retinal injuries, however, Müller cells undergo reactive gliosis; a key event in this process is the downregulation and redistribution of $\mathrm{K}_{\mathrm{ir}} 4.1$ channels, accompanied by a depolarisation of the membrane potential. This leads to a blockade of the neuroprotective glia-neurone interactions, which in turn causes a dramatic worsening of the survival conditions of the neurones. Further, reactive Müller cells actively contribute to neuronal cell death, by releasing toxic substances and cell death-mediating cytokines; finally, excessive glial cell proliferation causes retinal damage and detachment, which results in blindness.

Microglial motion: moving processes and brain defence. Microglial cells are the immunocompetent cells residing in the CNS, which, in essence, form the main brain defence system, activated upon various kinds of injuries and diseases. ${ }^{57}$ Microglia are of a myelomonocytic origin; the microglial precursor cells invade the brain during early embryonic development before closure of blood-brain barrier. ${ }^{57}$ In the normal brain, microglial cells are present in 
a

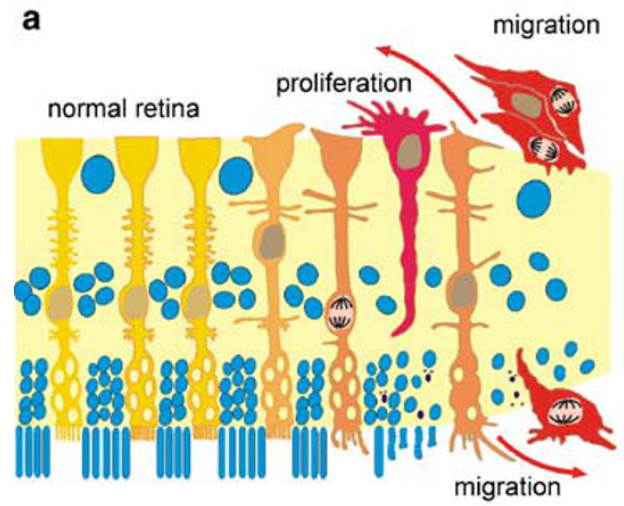

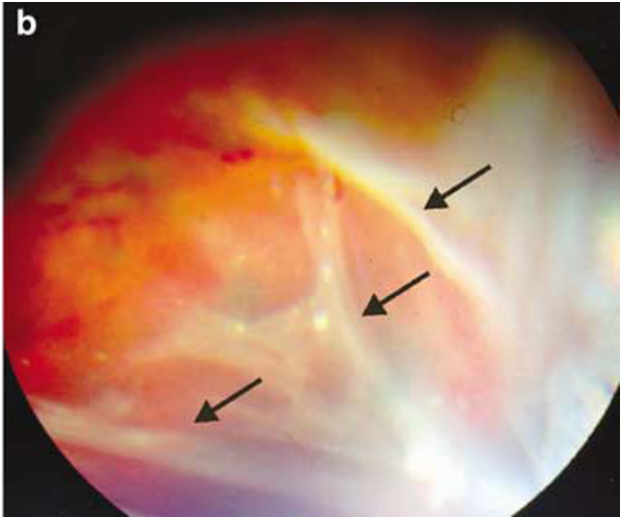

Figure 3 Extensive proliferation and migration of Müller cells as a detrimental complication of reactive gliosis. (a) Transition between normal Müller cells in a healthy retina (left side) and severe proliferative reactive gliosis in the injured retina with massive neurodegeneration (right side). (b) The outward migration of proliferating cells causes mechanical forces that lead to retinal folding (arrows) and detachment, described as proliferative vitreoretinopathy (PVR). Ophthalmoscopic image of a rabbit retina with experimentally induced PVR

the resting state, which is characterised by a small soma and numerous very thin and highly branched processes (hence these cells are also often called 'ramified'). ${ }^{57}$. In the cortex, each individual microglial cell is responsible for a clearly defined territory of about $150000 \mu \mathrm{m}^{3}$; the processes of resting cells are never in contact with each other. ${ }^{58}$ Brain insults set into the motion the activation of microglia, which is characterised by a complex pattern of biochemical and morphological changes. The activated microglia, very similarly to astrocytes, possess numerous mechanisms that are simultaneously neuroprotective and neurodestructive, depending on the severity of brain insult.

Up until recently resting, 'ramified' microglia have been considered as rather inactive and dormant cells, which dwell in the neuropil and wait for activation due to brain injuries of various nature. Many in vitro studies identified a plethora of substances, which cause microglia activation with morphological and functional transformations; these agents include endogenous substances such as chemokines, cytokines or metabolites such as IL1- $\beta$, IL-4, TNF $\alpha$, fractalkine, complement fragments or ATP, but also ectopic substances such as cell wall components of Gram-positive and -negative bacteria, lipopolysaccharides or lipoteichoic acid. ${ }^{59-61}$

Most of microglial studies performed so far, however, used acutely isolated brain preparations, which themselves can induce cellular activation by releasing various active substances from damaged tissue. This disadvantage could now be circumvented by employing two-photon laser-scanning microscopy (2P-LSM) on genetically modified mice carrying microglial markers, thus allowing noninvasive real-time visualisation of microglia in the brain proper. ${ }^{58,62}$ For this analysis, genetically modified mice were used in which replacement of the chemokine receptor CX3CR1 gene (also known as fractalkine receptor) by the enhanced green fluorescent protein (EGFP) leads to microglia-specific labelling. ${ }^{63}$ Because the EGFP is expressed in the cytoplasm, laser-scanning microscopy can reveal the complete cellular structure.

Using this model fluorescently labelled cells can be visualised transcranially through a thinned $(\sim 50 \mu \mathrm{m})$ window made in the skull bone. Confocal imaging revealed the typical shape of microglia: small rod-shaped somata with a radial extension of numerous thin and highly ramified processes (Figure 4). Microglial cells were found to be rather homogeneously distributed, suggestive of a territorial organisation. On average about 6000-7000 microglial cells occupied every $\mathrm{mm}^{3}$ of the brain volume. Interestingly, mice tolerated anaesthesia and imaging for more than $10 \mathrm{~h}$, which time was quite sufficient for long-term analysis of microglial motility. The real-time movies obtained with this technique highlight the enormous dynamics of permanent membrane extensions and process retractions. ${ }^{58}$ To penetrate the neuropile, the tips of extending processes form bulbous enlargements which spread into the neighbourhood at a speed of about 1-2 $\mu \mathrm{m}$ per min. After such an extension period, the processes were retracted and extended again into another direction. Interestingly, the cellular somata stayed very constant at their positions forming a three-dimensional microglial network. As the extent of random process dynamics stayed constant over several hours, it was concluded that it serves a type of brain surveillance. This regular surveillance pattern changes into a rapid response when the brain is damaged. Using energy of light delivered through 2P-LSM, micro-haemorrhages can be induced by focusing the scanning infrared laser onto a brain capillary for $30 \mathrm{~s}$ and increasing its power threefold. ${ }^{58}$ As soon as components of the blood arrive into the neuropil, microglial cells immediately send their processes to the lesion site. Processes are also being sent from rather distant regions (more than several hundred micrometres apart). Process tips impinging on the lesioned vessel broaden and form, together with processes from other cells, a tight mesh that soon seals the capillary. Similar targeted process extensions can be observed if single cells such as neurones or astrocytes are ablated by the infrared laser. ${ }^{62}$

The rapid movement of microglial processes is controlled by metabotropic $\mathrm{P}_{2} \mathrm{Y}_{12}$ purinorepecptores, as in $\mathrm{P} 2 \mathrm{Y}_{12}$ knockout mice localised microlesions do not induce rapid process extensions of microglia. ${ }^{64}$ Therefore, early microglial reactions to brain injury can be divided into at least three 

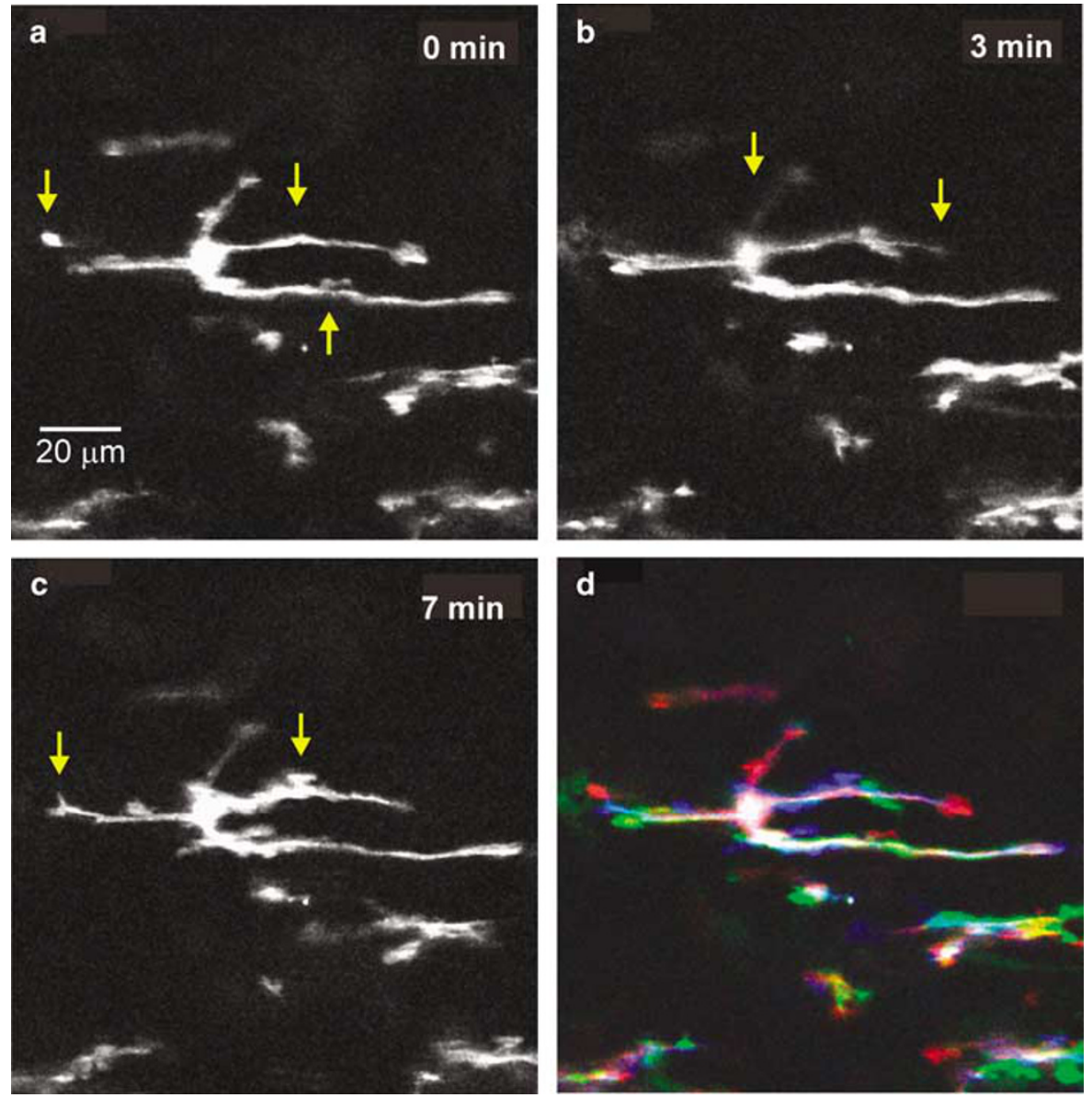

Figure 4 Time-lapse recording of microglia in the spinal cord of genetically modified mice in which EGFP is expressed from the CX3CR1 locus. (a-c) Snapshots of a microglial cell taken at times indicated. Microglial processes are longitudinally orientated along axonal fiber tracts. Some small membrane protrusions (arrows) emanate from the major processes within minutes, whereas others are retracted simultaneously. These terminal processes constantly survey their cellular neighbourhood. (d) Overlay of the images shown on (a-c), colour coded in red, green and blue. The static portion of the cell therefore appears in white and the moving processes in different colours

phases: first, associated with ATP/P2 $\mathrm{Y}_{12}$-mediated capability to sense acute lesions and initiate secondary responses such as process extension; second, which requires as yet unknown signals to control growth process towards the lesion site and a third phase which consists of the reorganisation of process tips directly at the injured area.

The white matters: oligodendroglia death and brain ischaemia. Oligodendrocytes are the major cell type of white matter, which in humans constitutes about $50 \%$ of the total brain volume. Oligodendroglia express glutamate receptors and transporters, and are highly vulnerable to excitotoxic and ischaemic insults (for recent reviews see Alberdi et al. ${ }^{65}$ ) Excessive activation of $\alpha$-amino-3-hydroxy-5methylisoxazole-4-propionic acid (AMPA), kainate or NMDA receptors in oligodendrocytes leads to $\mathrm{Ca}^{2+}$ overload and cell death. A central event to this process is accumulation of $\mathrm{Ca}^{2+}$ within mitochondria, which leads to the depolarisation of this organelle, increased production of oxygen free radicals, and release of proapoptotic factors which activate caspases (Figure 5).

Glutamate can also cause oligodendrocyte demise indirectly by inducing the release of toxic agents (such as TNF- $\alpha$ ) from microglia, which can potentiate glutamate oligotoxicity via inhibition of glutamate uptake. Indeed, inhibition of the expression and functioning of glutamate transporters in axonal tracts is sufficient to induce oligodendroglial loss and demyelination. ${ }^{66}$ Furthermore, glutamate at nontoxic concentrations can also induce oligodendrocyte death by sensitising these cells to complement attack. ${ }^{67}$ Complement toxicity is mediated by kainate, but not by AMPA, NMDA or metabotropic glutamate receptors and requires the formation of the membrane attack complex which in turn increases membrane conductance, induces $\mathrm{Ca}^{2+}$ overload and mitochondrial depolarisation as well as a rise in the level of reactive oxygen species. Treatment with the antioxidant Trolox and inhibition of poly(ADP-ribose) polymerase-1, but not of caspases, protected oligodendrocytes against damage induced by complement. This novel mechanism of glutamate-induced toxicity to oligodendrocytes is also shared by neurones and may be relevant to glutamate injury in acute and chronic neurological disease with primary or secondary inflammation.

Loss of oligodendrocytes with subsequent damage to white matter occurs in stroke, traumatic injury, neurodegenerative diseases, multiple sclerosis (MS) as well as in psychiatric diseases. ${ }^{17}$ Immature and adult oligodendrocytes are 


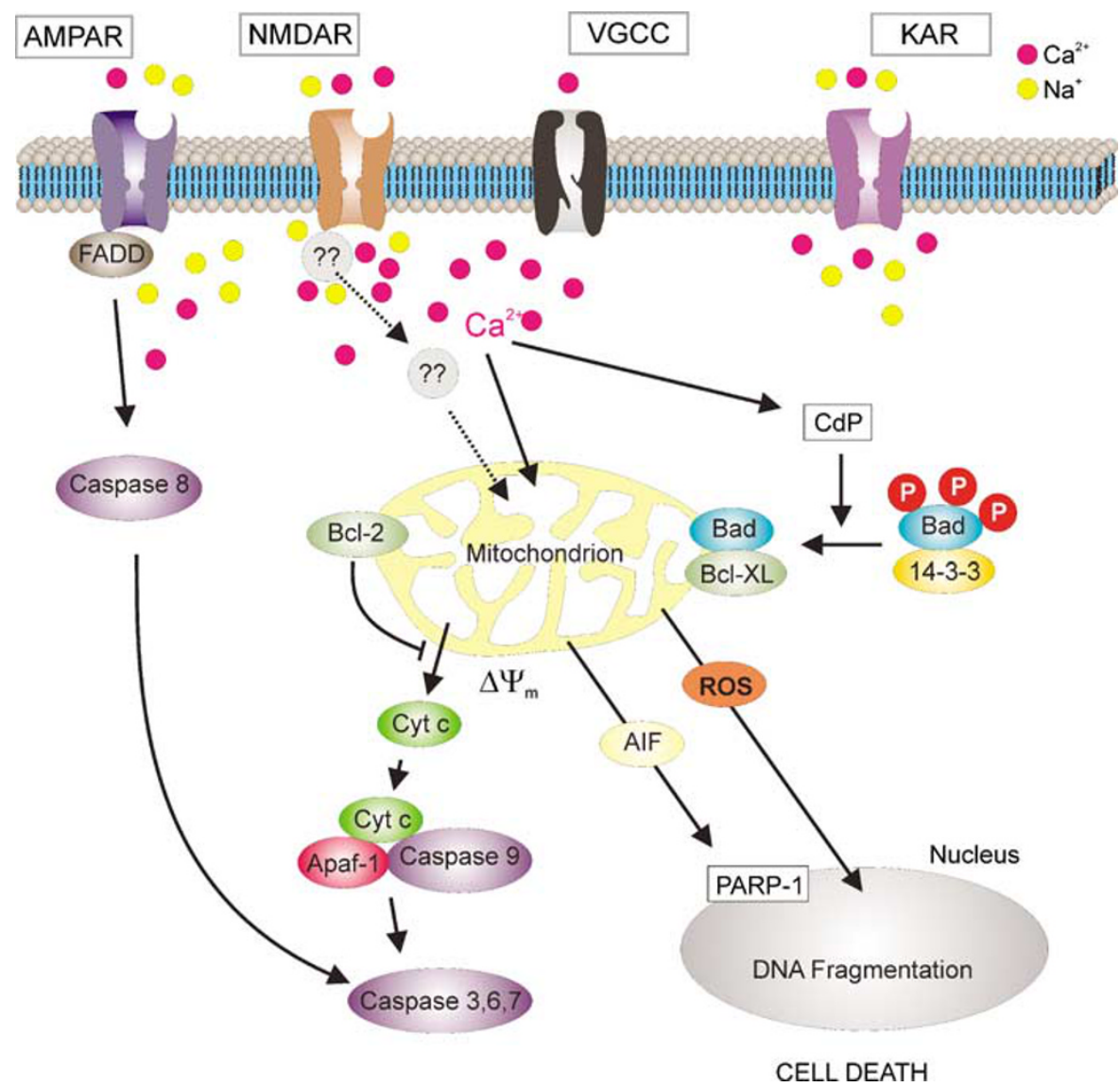

Figure 5 Signalling cascades triggered by activation of glutamate receptors induce oligodendrocyte death. Selective activation of AMPA receptors (AMPAR) and kainate receptors (KAR) leads to $\mathrm{Na}^{+}$and $\mathrm{Ca}^{2+}$ influx through the receptor channel complex. Subsequent depolarisation activates voltage-gated $\mathrm{Ca}^{2+}$ channels (VGCC) which contributes to $\left[\mathrm{Ca}^{2+}\right]_{\mathrm{i}}$ increase. $\mathrm{Ca}^{2+}$ overload induces rapid uptake by mitochondria, which results in attenuation of mitochondrial potential and an increase in the production of reactive oxygen species (ROS). Cytochrome $c$ (Cyt $c$ ) is released from depolarised mitochondria, interacts with apoptotic protease activating factor 1 (Apaf-1) and activates caspases. Other proapoptotic factors include apoptosis-inducing factor (AIF) which activates poly(ADP-ribose)polymerase-1 (PARP-1). In oligodendrocytes, insults channelled through Kai-R activate caspases 9 and 3 , whereas those activating AMPA-R induces apoptosis by recruiting caspase 8 , which truncates Bid, caspase 3 and PARP-1, or cause necrosis. In addition, $\mathrm{Ca}^{2+}$ influx triggered by Kai-R stimulation but not by AMPA-R activates calcineurin (CdP), which dephosphorylates Bad and facilitates apoptosis. Finally, activation of NMDA receptors (NMDA-R) also initiates oligodendrocyte death which is entirely dependent on $\mathrm{Ca}^{2+}$ influx; however, the molecular mechanisms activated by these receptors are not known yet. Abbreviations: FADD, Fas-associated death domain; 14-3-3, phosphoserine-binding protein 14-3-3

particularly sensitive to transient oxygen and glucose deprivation. Both NMDA and AMPA/kainate receptors are activated during ischaemia and their antagonists protect both oligodendrocytes and myelin. ${ }^{68}$ This feature is relevant to stroke as well as to preterm and perinatal ischaemia. Thus, in vivo models of stroke and cardiac arrest such as permanent middle cerebral artery occlusion and brief transient global ischaemia induce rapid oligodendroglial death. ${ }^{69}$ Few days after the insult, there is an increase in the number of oligodendroglial cells in areas bordering affected regions, ${ }^{70}$, as well as in the number of immature oligodendrocytes surrounding the lateral ventricles ${ }^{71}$ indicating that ischaemic damage to oligodendroglia can be compensated for, at least in part, by the generation and migration of new oligodendrocytes.

Preterm and perinatal ischaemia can cause periventricular leukomalacia (PVL), the main substrate for cerebral palsy, which is characterised by diffuse injury of white matter surrounding the lateral ventricles. White matter damage in PVL is largely related to hypoxia-ischaemia and reperfusion in the sick premature infant as a consequence of free radical injury, cytokine toxicity and excitotoxicity. Injury to oligodendrocyte progenitors, caused in part by glutamate and the subsequent derailment of $\mathrm{Ca}^{2+}$ homeostasis, contributes to the pathogenesis of myelination disturbances in this illness. ${ }^{72}$ In addition to this mechanism, glutamate-induced depletion of glutathione and the subsequent oxidative stress in PVL also contributes to damage to oligodendrocytes, which are sensitive to oxidative stress in part because of their high lipid and iron content. Notably, the vitamin $\mathrm{K}$ deficiency in preterm infants is a risk factor for developing PVL, and in turn its presence is protective against oxidative injury to immature oligodendrocytes. $^{73}$

Another illustrious example of white matter disease is MS, in which the immune system attacks the white matter of the brain and spinal cord, leading to disability and/or paralysis. Myelin and oligodendrocytes are lost owing to the release by immune cells of cytotoxic cytokines, autoantibodies and toxic amounts of glutamate. ${ }^{74}$ In agreement with this idea, experimental autoimmune encephalomyelitis (EAE), an animal model which exhibits the clinical and pathological features 
of MS, is alleviated by AMPA and kainate receptor antagonists. Remarkably, blockade of these receptors in combination with anti-inflammatory agents is effective even at an advanced stage of unremitting $E A E$, as assessed by increased oligodendrocyte survival and remyelination, and corresponding decreased paralysis, inflammation, CNS apoptosis and axonal damage. ${ }^{75}$

Glutamate levels are increased in acute MS lesions and in normal-appearing white matter in MS patients. ${ }^{76}$ Potential cellular sources contributing to enhanced glutamate levels in cerebrospinal fluid include activated microglia, which can release glutamate via the reversal of glutamate transporter function, a process which is potentiated under pathological conditions. ${ }^{74}$ In addition, oxidative stress may also contribute to the increase in glutamate concentrations in the extracellular space, because free radicals reduce the efficiency of glutamate transporters. ${ }^{74}$ Other factors which may contribute to perturbing glutamate homeostasis include altered activity of the glutamate producing enzyme glutaminase in activated macrophages/microglia in close proximity to dystrophic axons, ${ }^{77}$ and altered expression of the glutamate transporters excitatory amino-acid transporter type 1 (EAAT-1) and EAAT2 in oligodendrocytes as a consequence of enhanced exposure to the proinflammatory cytokine TNF $\alpha .{ }^{78}$ Overall, these alterations likely lead to high extracellular glutamate levels and an increased risk of oligodendrocyte excitotoxicity in MS.

In summary, oligodendrocytes display great vulnerability to excitotoxic insults mediated by glutamate receptors, a feature which is relevant to acute and chronic diseases involving white matter such as stroke and MS, respectively. The proper functioning of glutamate uptake is critical to prevent glutamate-induced damage to oligodendrocytes, and positive regulators of the expression of glutamate transporters have a protective potential, as they contribute to ischaemic tolerance after ischaemic preconditioning. ${ }^{79}$

Another set of molecular targets to prevent glutamate insults to oligodendrocytes lie downstream of glutamate receptor activation (see Figure 5). For instance, tetracyclines, which attenuate mitochondrial damage subsequent to insults including excitotoxicity, protect oligodendrocytes and white matter, making these antibiotics promising candidates for the treatment of acute and chronic diseases with oligodendrocyte loss. ${ }^{80}$ On the other hand, drugs supporting the management of $\mathrm{Ca}^{2+}$ overload subsequent to the activation of glutamate receptors may improve oligodendrocyte viability.

\section{Conclusions}

Increasing number of evidence indicates that glial cells shape neural networks. Thus, it is time to reconsider their role in brain functions and to ask whether they are the fulcrum in brain pathology. Indeed, various types of glia are involved into dysfunction and damage of the brain, and specific glial functions may play a key role in the triggering or in the progression of several brain pathologies. The identification of molecular actors in glia such as junctional proteins, functional purinergic and glutamatergic receptors or cell mobility should certainly be considered when studying neurologic disorders. Glial contribution to brain pathology in many cases takes two faces, either protective or deleterious. Understanding of the rules that govern this duality and its balance is yet nascent; however, it is clear that the further definition of reactive gliosis, which embraces different subclasses of glia will give important clues in the near future. These clues will identify the role of glia in neuroprotection, neural cells death and their repair, and may result in developing new strategies of treating the insulted brain.

Acknowledgements. CG research was supported by the CRPCEN; the studies carried out in CM's laboratory were supported by the Ministerio de Educación y Ciencia, Ministerio de Sanidad y Consumo, Gobierno Vasco and Universidad del País Vasco; FK was supported by grants from the Max Planck Society and the DFG; AR were supported by the DFG; AV research was supported by HIN and Alzheimer Research Trust (UK). The authors thank Dr. Thomas Pannicke for inspiring discussions about this paper.

1. Exner S. Entwurf zur physiologischen Erklärung der Psychischen Erscheinungen. Leipzig/ Vienna: Deiticke, 1894

2. Ramon y, Cajal S. Histologie du systeme nerveux de l'homme et des vertebres. Paris: Masson, 1909.

3. DeFelipe J, Alonso-Nanclares L, Arellano Jl. Microstructure of the neocortex: comparative aspects. J Neurocytol 2002; 31: 299-316.

4. Oberheim NA, Wang X, Goldman S, Nedergaard M. Astrocytic complexity distinguishes the human brain. Trends Neurosci. 2006; 29: 547-553.

5. Sherwood CC, Stimpson CD, Raghanti MA, Wildman DE, Uddin M, Grossman LI et al. Evolution of increased glia-neuron ratios in the human frontal cortex. Proc Natl Acad Sci USA 2006; 103: 13606-13611.

6. Retzius G. Biologische Untersuchungen, Vols 5, 6. Stockholm: Verlag Von, Gustav, Fischer in Jena, 1894.

7. Colombo JA, Reisin HD. Interlaminar astroglia of the cerebral cortex: a marker of the primate brain. Brain Res 2004; 1006: 126-131.

8. Haydon PG, Carmignoto G. Astrocyte control of synaptic transmission and neurovascular coupling. Physiol Rev 2006; 86: 1009-1031.

9. Verkhratsky A. Calcium ions and integration in neural circuits. Acta Physiol (Oxf) 2006; 187 357-369.

10. Volterra A, Meldolesi J. Astrocytes, from brain glue to communication elements: the revolution continues. Nat Rev Neurosci 2005; 6: 626-640.

11. Zonta M, Angulo MC, Gobbo S, Rosengarten B, Hossmann KA, Pozzan T et al. Neuron-toastrocyte signaling is central to the dynamic control of brain microcirculation. Nat Neurosc 2003; 6 : 43-50.

12. Magistretti PJ. Neuron-glia metabolic coupling and plasticity. J Exp Biol 2006; 209 : 2304-2311.

13. Danbolt NC. Glutamate uptake. Prog Neurobiol 2001; 65: 1-105.

14. Kofuji $P$, Newman EA. Potassium buffering in the central nervous system. Neuroscience 2004; 129: 1045-1056.

15. Simard $M$, Nedergaard $M$. The neurobiology of glia in the context of water and ion homeostasis. Neuroscience 2004; 129: 877-896.

16. Pekny M, Nilsson M. Astrocyte activation and reactive gliosis. Glia 2005; 50: 427-434

17. Matute C, Domercq M, Sanchez-Gomez MV. Glutamate-mediated glial injury: mechanisms and clinical importance. Glia 2006; 53: 212-224.

18. Kettenmann H. Triggering the brain's pathology sensor. Nat Neurosci 2006; 9: 1463-1464.

19. Nedergaard M, Dirnagl U. Role of glial cells in cerebral ischemia. Glia 2005; 50: 281-286.

20. Westbrook GL. Glutamate receptors and excitotoxicity. Res Publ Assoc Res Nerv Ment Dis 1993; 71: 35-50.

21. Verkhratsky A, Kirchhoff F. NMDA receptors in glia. Neuroscientist 2007; 13: 28-37.

22. Nicotera $P$, Bellomo G, Orrenius $S$. Calcium-mediated mechanisms in chemically induced cell death. Annu Rev Pharmacol Toxicol 1992; 32: 449-470.

23. Allen NJ, Karadottir R, Attwell D. Reversal or reduction of glutamate and GABA transport in CNS pathology and therapy. Pflugers Arch 2004; 449: 132-142.

24. Contreras JE, Sanchez HA, Veliz LP, Bukauskas FF, Bennett MV, Saez JC. Role of connexin-based gap junction channels and hemichannels in ischemia-induced cell death in nervous tissue. Brain Res Brain Res Rev 2004; 47: 290-303.

25. Budd SL, Lipton SA. Calcium tsunamis: do astrocytes transmit cell death messages via gap junctions during ischemia? Nat Neurosci 1998; 1: 431-432.

26. Giaume $\mathrm{C}, \mathrm{McC}$ arthy $\mathrm{KD}$. Control of gap-junctional communication in astrocytic networks Trends Neurosci 1996; 19: 319-325.

27. Spray DC, Ye ZC, Ransom BR. Functional connexin 'hemichannels': a critical appraisal. Glia 2006; 54: 758-773.

28. Bruzzone R, Giaume C. Connexins and information transfer through glia. Adv. Exp. Med. Biol. 1999; 468: 321-337. 
29. Tabernero A, Medina JM, Giaume C. Glucose metabolism and proliferation in glia: role of astrocytic gap junctions. J Neurochem 2006; 99: 1049-1061.

30. Blomstrand F, Giaume C. Kinetics of endothelin-induced inhibition and glucose permeability of astrocyte gap junctions. J Neurosci Res 2006; 83: 996-1003.

31. Blomstrand F, Venance L, Siren AL, Ezan P, Hanse E, Glowinski J et al. Endothelins regulate astrocyte gap junctions in rat hippocampal slices. Eur J Neurosci 2004; 19: 1005-1015.

32. D'Ambrosio R, Wenzel J, Schwartzkroin PA, McKhann II GM, Janigro D. Functiona specialization and topographic segregation of hippocampal astrocytes. J Neurosci 1998 18: $4425-4438$

33. Nagy Jl, Dudek FE, Rash JE. Update on connexins and gap junctions in neurons and glia in the mammalian nervous system. Brain Res Brain Res Rev 2004; 47: 191-215.

34. Filippov MA, Hormuzdi SG, Fuchs EC, Monyer H. A reporter allele for investigating connexin 26 gene expression in the mouse brain. Eur J Neurosci. 2003; 18: 3183-3192.

35. Nagy Jl, Li X, Rempel J, Stelmack G, Patel D, Staines WA et al. Connexin26 in adult roden central nervous system: demonstration at astrocytic gap junctions and colocalization with connexin30 and connexin43. J Comp Neurol 2001; 441: 302-323.

36. Rash JE, Duffy HS, Dudek FE, Bilhartz BL, Whalen LR, Yasumura T. Grid-mapped freezefracture analysis of gap junctions in gray and white matter of adult rat central nervous system, with evidence for a 'panglial syncytium' that is not coupled to neurons. J Comp Neurol 1997; 388: 265-292.

37. Theis M, Sohl G, Eiberger J, Willecke K. Emerging complexities in identity and function of glial connexins. Trends Neurosci 2005; 28: 188-195.

38. Venance L, Cordier J, Monge M, Zalc B, Glowinski J, Giaume C. Homotypic and heterotypic coupling mediated by gap junctions during glial cell differentiation in vitro. Eur J Neurosci 1995; 7: 451-461.

39. Altevogt BM, Paul DL. Four classes of intercellular channels between glial cells in the CNS J Neurosci 2004; 24: 4313-4323.

40. Eugenin EA, Eckardt D, Theis M, Willecke K, Bennett MV, Saez JC. Microglia at brain stab wounds express connexin 43 and in vitro form functional gap junctions after treatment with interferon-gamma and tumor necrosis factor-alpha. Proc Natl Acad Sci USA 2001; 98 4190-4195

41. Rouach N, Avignone E, Meme W, Koulakoff A, Venance L, Blomstrand F et al. Gap junctions and connexin expression in the normal and pathological central nervous system. Biol Cell 2002; 94: 457-475

42. John GR, Scemes E, Suadicani SO, Liu JS, Charles PC, Lee SC et al. IL-1beta differentially regulates calcium wave propagation between primary human fetal astrocytes via pathways involving P2 receptors and gap junction channels. Proc Natl Acad Sci USA 1999; 96: 11613-11618.

43. Hinkerohe D, Smikalla D, Haghikia A, Heupel K, Haase CG, Dermietzel R et al. Effects of cytokines on microglial phenotypes and astroglial coupling in an inflammatory coculture model. Glia 2005; 52: 85-97.

44. Perez Velazquez JL, Frantseva MV, Naus CC. Gap junctions and neuronal injury: protectants or executioners? Neuroscientist 2003; 9: 5-9.

45. Bringmann A, Pannicke T, Grosche J, Francke M, Wiedemann P, Skatchkov SN et al. Muller cells in the healthy and diseased retina. Prog Retin Eye Res 2006; 25: 397-424.

46. Kofuji P, Biedermann B, Siddharthan V, Raap M, Iandiev I, Milenkovic I et al. Kir potassium channel subunit expression in retinal glial cells: implications for spatial potassium buffering Glia 2002; 39: 292-303.

47. Newman EA. Regional specialization of retinal glial cell membrane. Nature 1984; 309 155-157.

48. Bringmann A, Reichenbach A, Wiedemann P. Pathomechanisms of cystoid macular edema. Ophthalmic Res 2004; 36: 241-249.

49. Barnett NL, Pow DV, Robinson SR. Inhibition of Muller cell glutamine synthetase rapidly impairs the retinal response to light. Glia 2000; 30: 64-73.

50. Francke $M$, Faude $F$, Pannicke $T$, Bringmann $A$, Eckstein $P$, Reichelt $W$ et al Electrophysiology of rabbit Muller (glial) cells in experimental retinal detachment and PVR Invest Ophthalmol Vis Sci 2001; 42: 1072-1079.

51. Pannicke T, Uckermann O, landiev I, Biedermann B, Wiedemann P, Perlman I et al Altered membrane physiology in Muller glial cells after transient ischemia of the rat retina. Glia 2005; 50: 1-11.

52. Kobayashi M, Kuroiwa T, Shimokawa R, Okeda R, Tokoro T. Nitric oxide synthase expression in ischemic rat retinas. Jpn J Ophthalmol 2000; 44: 235-244.

53. Pierce EA, Avery RL, Foley ED, Aiello LP, Smith LE. Vascular endothelial growth factor vascular permeability factor expression in a mouse model of retinal neovascularization. Proc Natl Acad Sci USA 1995; 92: 905-909.
54. Shima DT, Adamis AP, Ferrara N, Yeo KT, Yeo TK, Allende R et al. Hypoxic induction of endothelial cell growth factors in retinal cells: identification and characterization of vascular endothelial growth factor (VEGF) as the mitogen. Mol Med 1995; 1: 182-193.

55. Nakazawa T, Matsubara A, Noda K, Hisatomi T, She H, Skondra D et al. Characterization of cytokine responses to retinal detachment in rats. Mol Vis 2006; 12: 867-878.

56. Pastor JC. Proliferative vitreoretinopathy: an overview. Surv Ophthalmol 1998; 43: 3-18.

57. Kreutzberg GW. Microglia: a sensor for pathological events in the CNS. Trends Neurosci 1996; 19: 312-318

58. Nimmerjahn A, Kirchhoff F, Helmchen F. Resting microglial cells are highly dynamic surveillants of brain parenchyma in vivo. Science 2005; 308: 1314-1318.

59. Moller T, Nolte C, Burger R, Verkhratsky A, Kettenmann H. Mechanisms of C5a and C3a complement fragment-induced $\left[\mathrm{Ca}^{2+}\right]_{\text {; }}$ signaling in mouse microglia. J Neurosci 1997; 17: 615-624.

60. Schwartz M, Butovsky O, Bruck W, Hanisch UK. Microglial phenotype: is the commitment reversible? Trends Neurosci 2006; 29: 68-74.

61. Farber K, Kettenmann H. Purinergic signaling and microglia. Pflugers Arch 2006; 452: 615-621.

62. Davalos D, Grutzendler J, Yang G, Kim JV, Zuo Y, Jung S et al. ATP mediates rapid microglial response to local brain injury in vivo. Nat Neurosci 2005; 8: 752-758.

63. Jung S, Aliberti J, Graemmel P, Sunshine MJ, Kreutzberg GW, Sher A et al. Analysis of fractalkine receptor $\mathrm{CX}_{3} \mathrm{CR} 1$ function by targeted deletion and green fluorescent protein reporter gene insertion. Mol Cell Biol 2000; 20: 4106-4114.

64. Haynes SE, Hollopeter G, Yang G, Kurpius D, Dailey ME, Gan WB et al. The P2Y receptor regulates microglial activation by extracellular nucleotides. Nat Neurosci 2006; 9 : 1512-1519.

65. Alberdi E, Sanchez-Gomez MV, Matute C. Calcium and glial cell death. Cell Calcium 2005; 38: 417-425.

66. Domercq M, Etxebarria E, Perez-Samartin A, Matute C. Excitotoxic oligodendrocyte death and axonal damage induced by glutamate transporter inhibition. Glia 2005; 52: 36-46.

67. Alberdi E, Sanchez-Gomez MV, Torre I, Domercq M, Perez-Samartin A, Perez-Cerda F et al. Activation of kainate receptors sensitizes oligodendrocytes to complement attack. J Neurosci 2006; 26: 3220-3228.

68. Matute C. Oligodendrocyte NMDA receptors: a novel therapeutic target. Trends $\mathrm{Mol} \mathrm{Med}$ 2006; 12: 289-292.

69. Petito CK, Olarte JP, Roberts B, Nowak Jr TS, Pulsinelli WA. Selective glial vulnerability following transient global ischemia in rat brain. J Neuropathol Exp Neurol 1998; 57: 231-238

70. Mandai K, Matsumoto M, Kitagawa K, Matsushita K, Ohtsuki T, Mabuchi T et al. Ischemic damage and subsequent proliferation of oligodendrocytes in focal cerebral ischemia. Neuroscience 1997; 77: 849-861.

71. Gottlieb M, Domercq M, Matute C. Altered expression of the glutamate transporter EAAC1 in neurons and immature oligodendrocytes after transient forebrain ischemia. J Cereb Blood Flow Metab 2000; 20: 678-687.

72. Back SA, Rivkees SA. Emerging concepts in periventricular white matter injury. Semin Perinatol 2004; 28: 405-414.

73. Li J, Lin JC, Wang H, Peterson JW, Furie BC, Furie B et al. Novel role of vitamin K in preventing oxidative injury to developing oligodendrocytes and neurons. J Neurosci 2003; 23: 5816-5826.

74. Matute C, Alberdi E, Domercq M, Perez-Cerda F, Perez-Samartin A, Sanchez-Gomez MV. The link between excitotoxic oligodendroglial death and demyelinating diseases. Trends Neurosci 2001; 24: 224-230.

75. Kanwar JR, Kanwar RK, Krissansen GW. Simultaneous neuroprotection and blockade of inflammation reverses autoimmune encephalomyelitis. Brain 2004; 127: 1313-1331.

76. Srinivasan R, Sailasuta N, Hurd R, Nelson S, Pelletier D. Evidence of elevated glutamate in multiple sclerosis using magnetic resonance spectroscopy at 3T. Brain 2005; 128: 1016-1025

77. Werner P, Pitt D, Raine CS. Multiple sclerosis: altered glutamate homeostasis in lesions correlates with oligodendrocyte and axonal damage. Ann Neurol 2001; 50: 169-180.

78. Vallejo-Illarramendi A, Domercq M, Perez-Cerda F, Ravid R, Matute C. Increased expression and function of glutamate transporters in multiple sclerosis. Neurobiol Dis 2006; 21: 154-164.

79. Romera C, Hurtado O, Botella SH, Lizasoain I, Cardenas A, Fernandez-Tome P et al. In vitro ischemic tolerance involves upregulation of glutamate transport partly mediated by the TACE/ADAM17-tumor necrosis factor-alpha pathway. J Neurosci 2004; 24: 1350-1357.

80. Domercq M, Matute C. Neuroprotection by tetracyclines. Trends Pharmacol Sci 2004; 25: $609-612$ 